\title{
Temperature extremes in Europe: overview of their driving atmospheric
}

patterns

\section{Andrade ${ }^{1,2}$, S. M. Leite ${ }^{2}$ and J. A. Santos ${ }^{2}$}

[1] \{nstituto Politécnico de Tomar, Unidade Departamental de Matemática e Física, Estrada da Serra, Quinta do Contador, 2300-313 Tomar, Portugal, c.andrade@ipt.pt\}

[2]\{CITAB, University of Trás-os-Montes e Alto Douro, 5000-801 Vila Real, Portugal, jsantos@utad.pt\}

\section{Supplementary material}

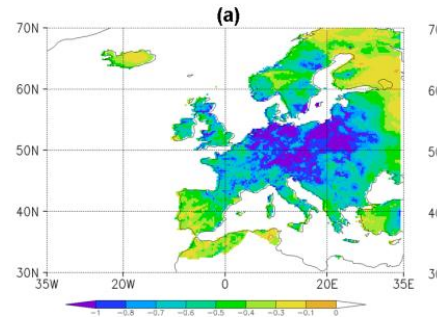

(d)

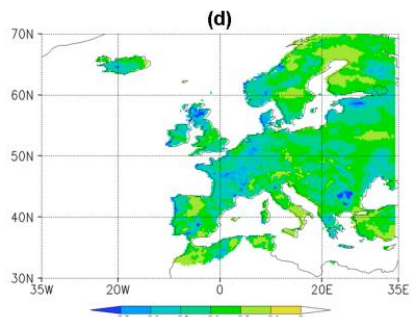

(g)

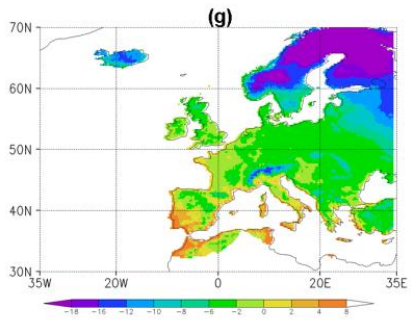

(j)

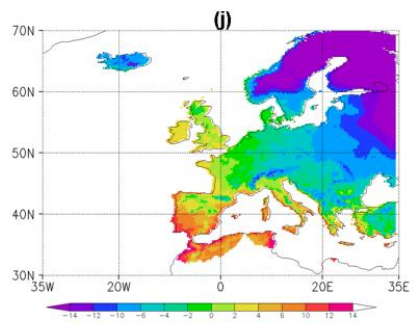

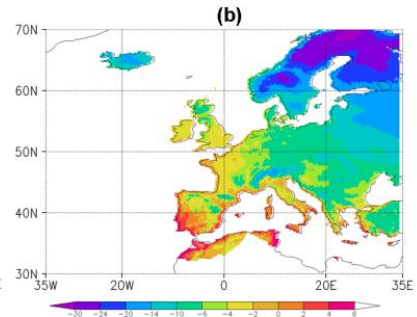

(e)

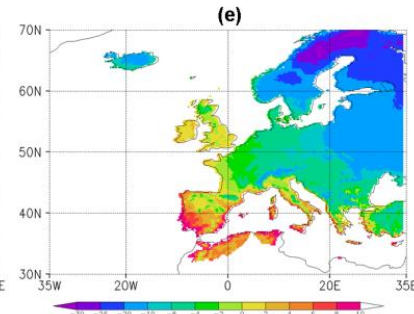

(h)

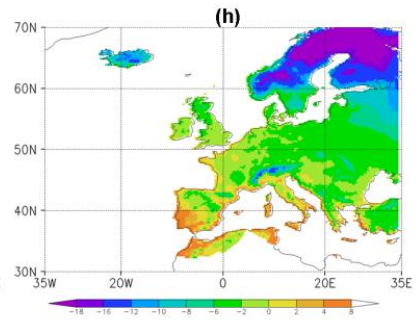

(k)

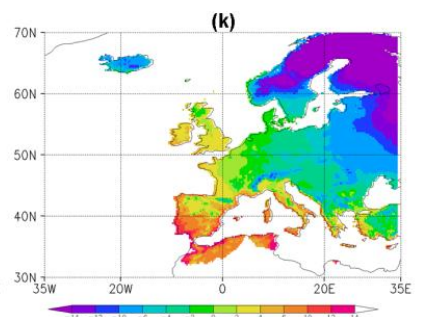

(c)

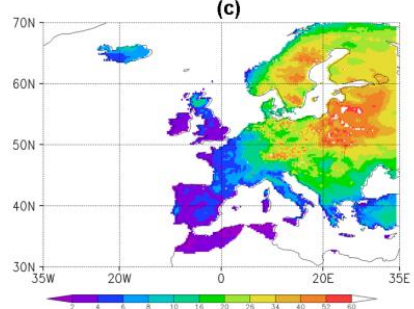

(f)

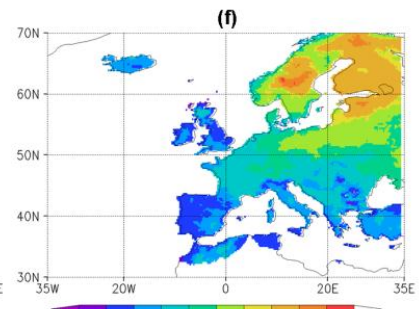

(i)

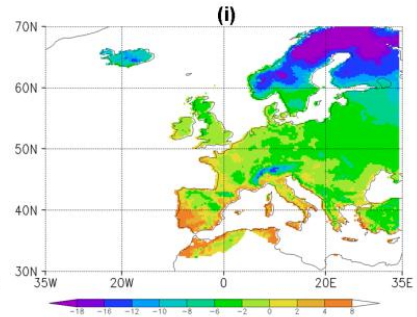

(I)

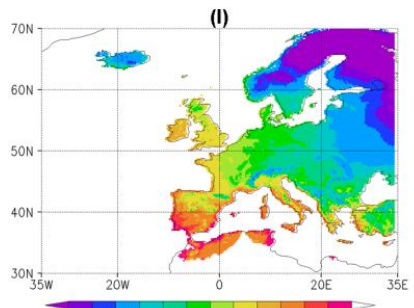

Fig. S1. Shape parameter of the GEV distribution for the spring (a) TNN and (d) TXX. Mean patterns (in ${ }^{\circ} \mathrm{C}$ ) of the GEV distribution for (b) TNN and (e) TXX. Variance patterns (in ${ }^{\circ} \mathrm{C}^{2}$ ) of the GEV distribution for the spring (c) TNN and (f) TXX. Patterns of the temperatures $\left(\right.$ in ${ }^{\circ} \mathrm{C}$ ) associated with the 5-, 10-, 20-yr return periods for the spring (g-i) TNN and $(\mathrm{j}-1)$ TXX. 

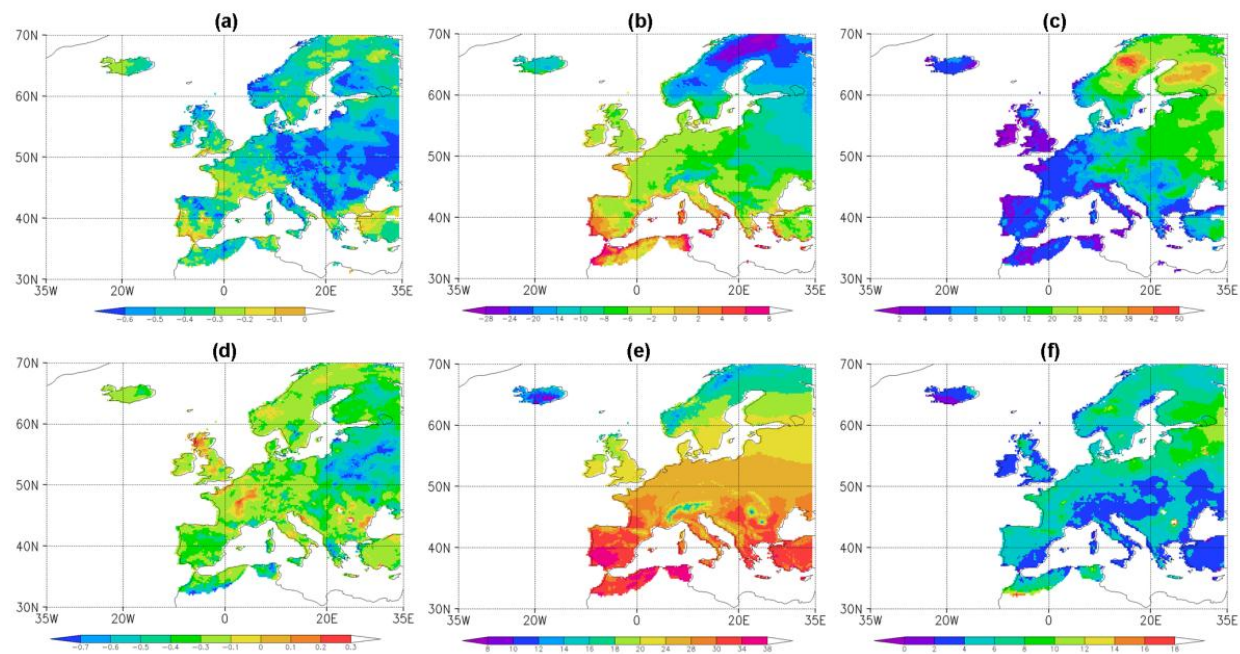

(e)

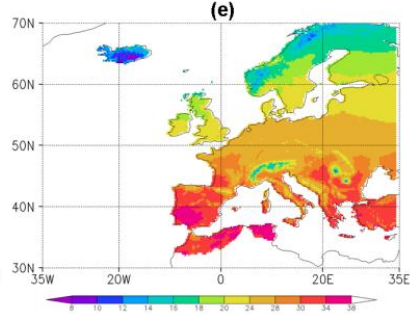

(f)
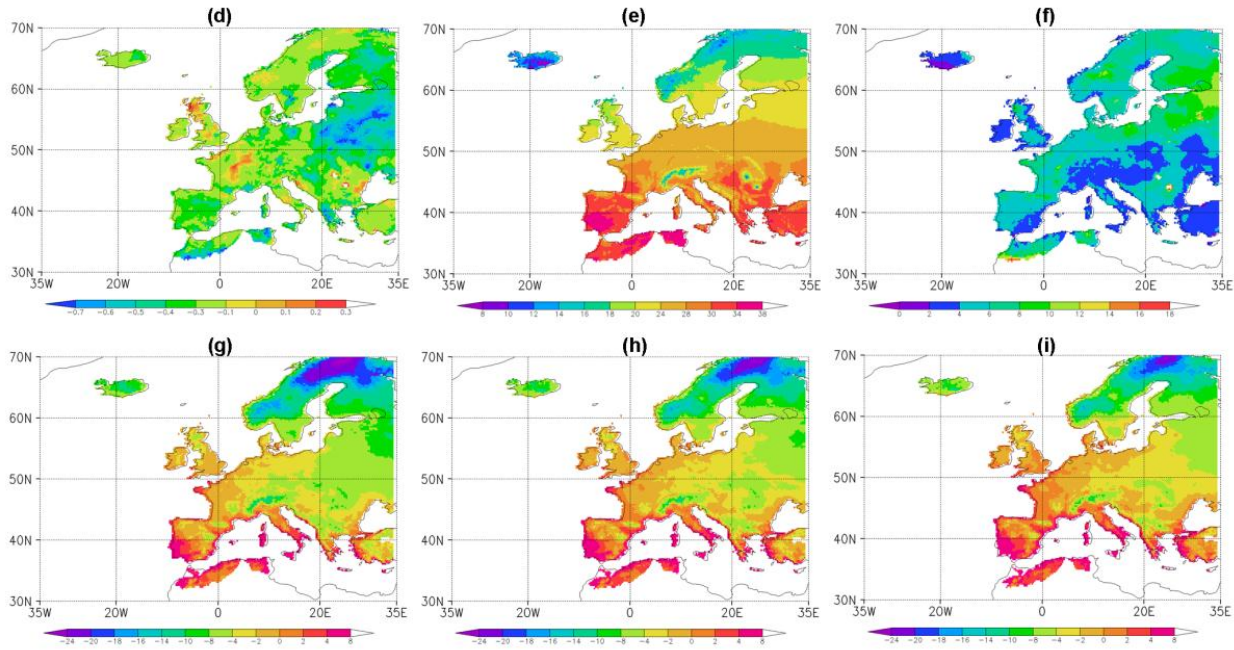

(j)
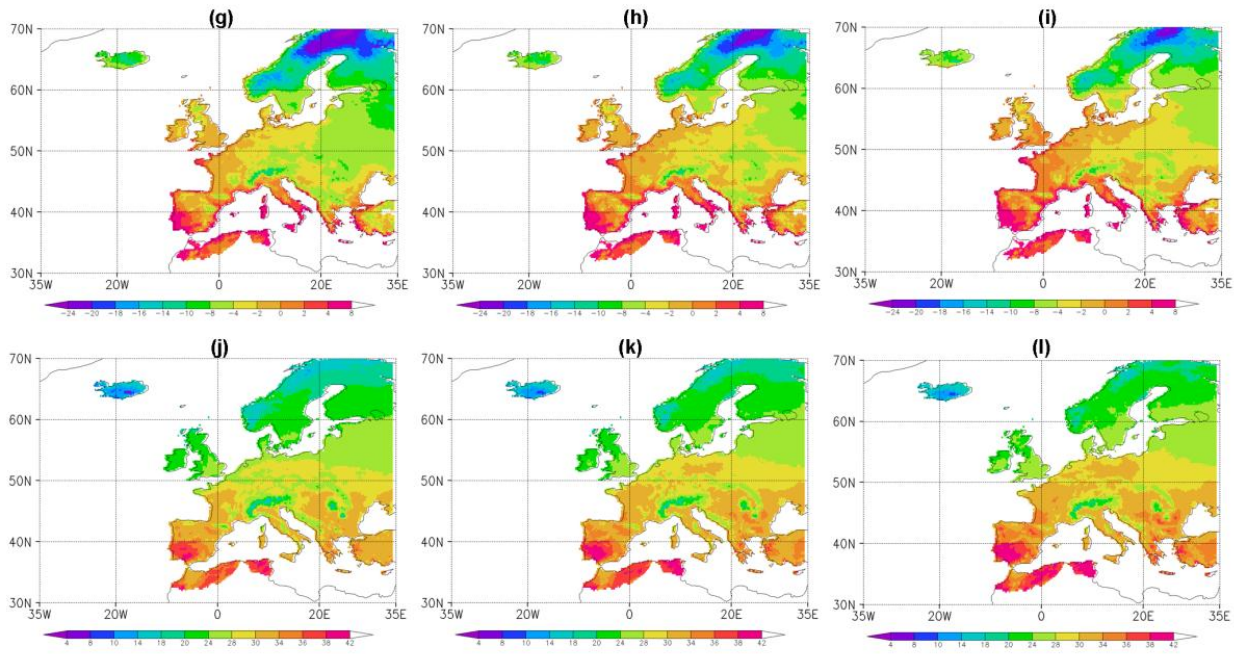

Fig. S2. As in Figure S1 but for the autumn. 

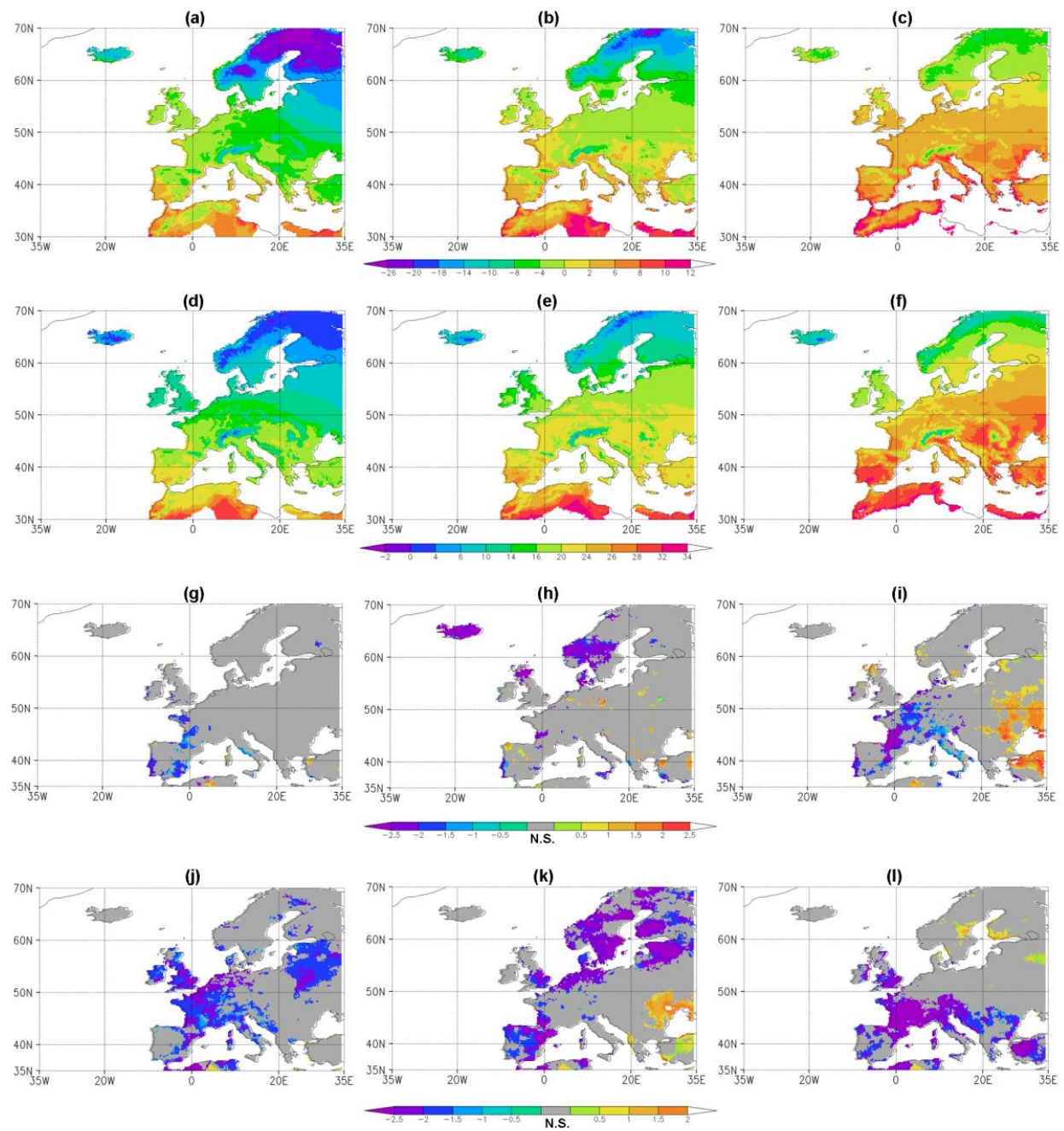

Fig. S3. Monthly mean TN10p (in ${ }^{\circ} \mathrm{C}$ ) for (a) March, (b) April and (c) May in the period 1961-2010; (d, e, f) as in $(a, b, c)$ but for monthly mean TX90p (in $\left.{ }^{\circ} \mathrm{C}\right)$. The corresponding statistically significant linear trends (in days. $\mathrm{yr}^{-1}$ ) at the $95 \%$ confidence level (Spearman-rho test) of the monthly mean TN10p for (g) March, (h) April and (i) May; $(j, k, 1)$ as in $(g, h, i)$ but for the monthly mean TX90p (N.S. for not significant) 

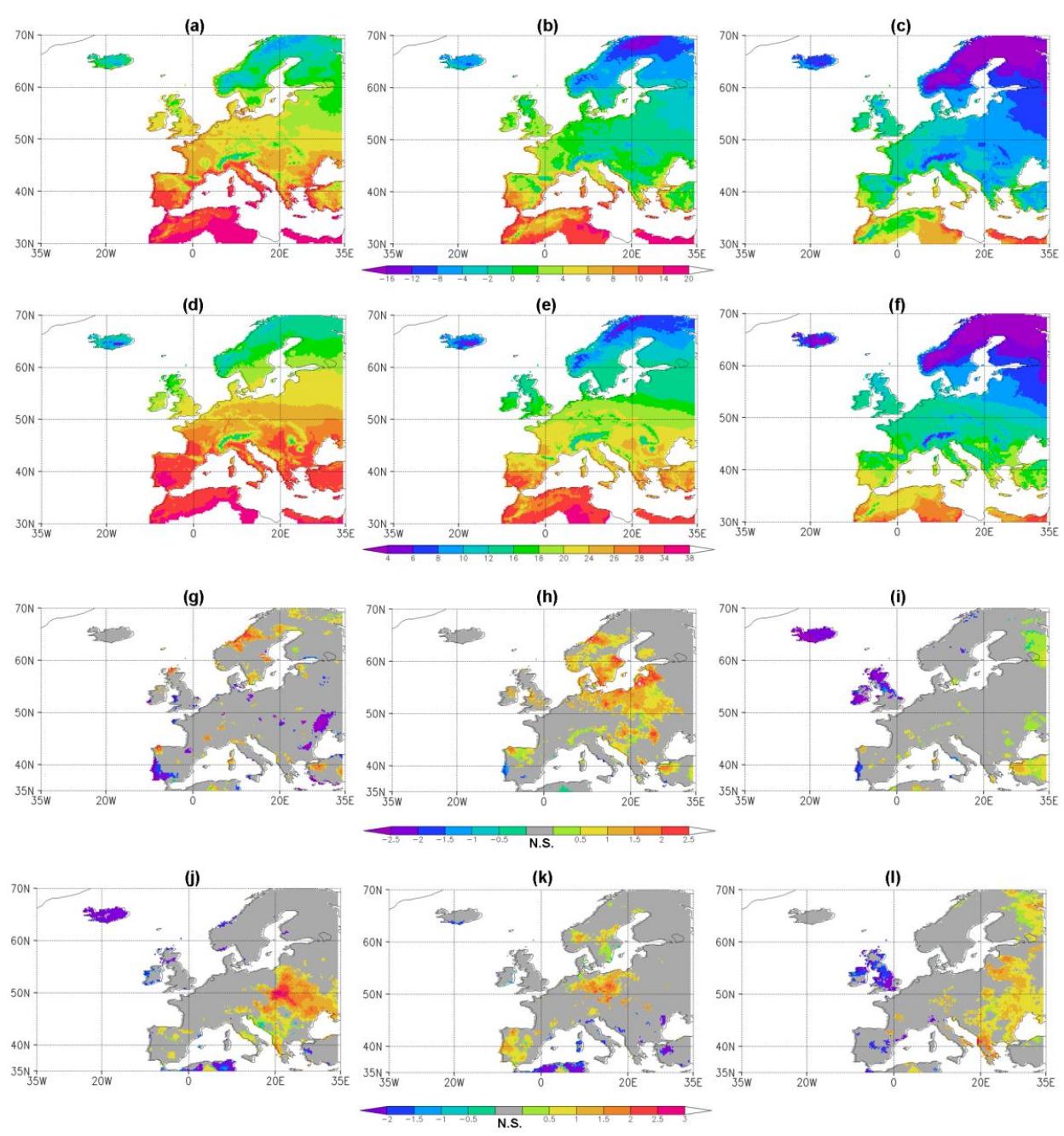

Fig. S4. Monthly mean TN10p (in ${ }^{\circ} \mathrm{C}$ ) for (a) September, (b) October and (c) November in the period 1961-2010; (d, e, f) as in (a, b, c) but for monthly mean TX90p (in $\left.{ }^{\circ} \mathrm{C}\right)$. The corresponding statistically significant linear trends (in days.yr ${ }^{-1}$ ) at the $95 \%$ confidence level (Spearman-rho test) of the monthly mean TN10p for (g) September, (h) October and (i) November; (j, k, l) as in (g, h, i) but for the monthly mean TX90p (N.S. for not significant) 